\title{
Esophageal stricture associated with alendronate use
}

\author{
Asit K. Paul MD PhD, Mysore Seetharaman MD
}

$\mathrm{A}$

n 84-year-old woman presented with a one-year history of intermittent chest pain and progressive difficulty swallowing while eating solid food. She had no history of gastrointestinal problems. She had been taking alendronate sodium (a 70-mg tablet, once a week) for the past year for the treatment of osteoporosis. Physical examination was unremarkable.

A computed tomographic scan of the chest (Figure 1A) and barium swallow radiograph (Figure 1B) showed a moderately dilated mid esophagus with distal tapering. Esophagogastroscopy showed a dilated midesophagus with discrete ulcerations and a short-segment tight stricture near the gastroesophageal junction. The results of histological analysis of a biopsy specimen of the midesophagus were consistent with an ulcer with active esophagitis, and staining of the specimen was negative for fungus and viral inclusions. The patient was instructed to stop taking alendronate and underwent an endoscopic dilatation and botulinum toxin A treatment for the stricture. She remained free of symptoms at last follow-up.

The temporal relation between the onset of symptoms and start of alendronate therapy, the absence of symptoms before use of alendronate and the absence of evidence of infection or malignancy suggest that alendronate was the likely causative agent of our patient's esophagitis, which lead to a stricture and proximal dilatation of her esophagus. Nevertheless, the possibility of clinically silent gastroesophageal reflux disease cannot be conclusively ruled out.

The association between alendronate use and esophageal adverse effects such as acute esophagitis, esophageal ulceration and erosive esophagitis is well recognized. ${ }^{1}$ These adverse effects are caused by direct contact of the drug with the esophageal mucosa. Reports of stricture formation from alendronate use are rare in the

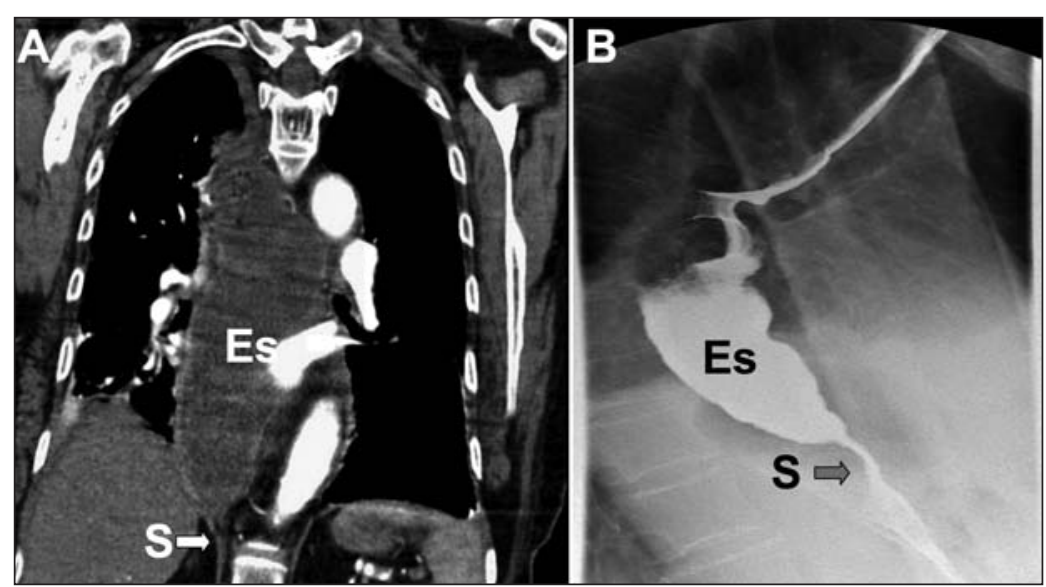

Figure 1: (A) Coronal view of the computed tomographic scan of the chest and (B) upright oblique radiograph from a barium swallow study of an 84-year-old woman with progressive dysphagia, showing dilation of the midesophagus (Es) and a distal short-segment tight stricture (S).

literature. ${ }^{1-4}$ Stricture may be caused by continued esophageal inflammation as a result of longterm use. Since the approval of alendronate in Canada in 1996, four cases of esophageal stricture have been reported to Health Canada. ${ }^{5} \mathrm{Re}$ cently, esophageal cancer has been reported to be associated with long-term use of alendronate. ${ }^{6}$ Esophageal symptoms in a patient undergoing long-term alendronate therapy therefore warrant assessment.

\section{References}

1. Ryan JM, Kelsey P, Ryan BM, et al. Alendronate-induced esophagitis: case report of a recently recognized form of severe esophagitis with esophageal stricture - radiographic features. Radiology 1998;206:389-91.

2. Naylor G, Davies MH. Oesophageal stricture associated with alendronic acid. Lancet 1996;348:1030-1.

3. Levine J, Nelson D. Esophageal stricture associated with alendronate therapy. Am J Med 1997;102:489-91.

4. Yue QY, Mortimer O. Alendronate-risk for esophageal stricture. J Am Geiatr Soc 1998;46:1581-2.

5. Health Canada. Canada Vigilance Adverse Reaction Online Database. Available: www.hc-sc.gc.ca/dhp-mps/medeff/databas don/index-eng.php (accessed 2010 June 8)

6. Wysowski DK. Reports of esophageal cancer with oral bisphosphonate use. N Engl J Med 2009;360:89-90.
Competing interests: None declared.

This article has been peer reviewed.

Affiliations: From the Department of Internal Medicine, Rochester General Hospital, Rochester, NY

Correspondence to: Dr. Mysore Seetharaman, mysore.seetharaman@roche stergeneral.org

CMAJ 2011. DOI:10.1503 /cmaj.100415 